\title{
Monumentos, monstruos y espectros: la figura del proletario en Argentina (1920-1950).
}

\section{Monuments, Monsters and Specters: the Proletarian's Figure in Argentina (1920-1950).}

\section{Resumen}

La centralidad que adquiere el trabajo durante las primeras décadas del siglo XX en Argentina responde a un contexto específico. Se trata de un período de intensa industrialización en el que una multitud de inmigrantes llegaba cotidianamente a las grandes ciudades. La fábrica y la oficina emergieron, entonces, como los motores de nuevas formas de incorporar esas masas a la ciudadanía. El trabajo se volvió un poderoso mecanismo para asignar una identidad y disciplinar a los sujetos: el intimidante forastero se convertía a partir de su lugar en el aparato de producción en el "obrero", en el "oficinista". 0, directamente, en el proletario. Sin embargo, en la representación también se jugaba la resistencia. A partir del análisis de un contexto cultural espeso (que incluye discursos políticos, revistas de izquierda, así como iconografía o experimentos culturales en torno al trabajo) en este artículo exploro la forma en que durante las primeras décadas del siglo veinte la representación del proletario se transformó en un campo disputas para distintos modos de politización de los sujetos.

Palabras claves 


\begin{abstract}
In the particular context of the Argentine political and cultural field, the centrality of labor during the first half of the twentieth century has its own specific consequences. In Buenos Aires, such decades were witness to an intense period of industrialization marked by crowds of immigrants arriving daily into the city in search of work. The factory and the office emerged as the engines of a new way to incorporate masses of immigrants into the citizen body: the intimidating stranger became "a laborer" or "a clerk." Or, straightaway, "a worker." Thus, labor became a powerful mechanism whereby subjects were assigned an identity and disciplined. However, the resistance was also part of that process: by closely examining a variety of documents from a thick cultural context, including political speeches, left-wing magazines, but also iconogrophy and cultural experiments, I argue that during the first half of the twentieth century the representation of workers becomes a battle field for several modes of politicizing the subject.
\end{abstract}

Keywords

proletarian, Florida, Boedo, Claridad, Castelnuovo, peronism, peronism.

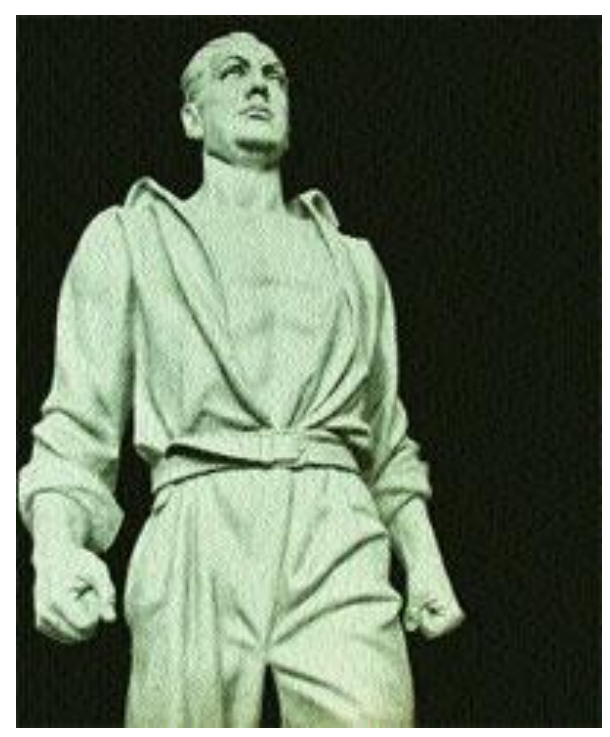

Ilustración 1. Imagen del proyecto al descamisado. 
CATEDRAL Tomada: Revista de crítica literaria latinoamericana / Journal of Latin American Literary Criticism Monumentos, monstruos y espectros: la figura del proletario en Argentina (1920-1950)

En 1951, el presidente argentino Juan Domingo Perón proyectó la construcción de un colosal monumento al Descamisado ${ }^{1}$. A través de un proletario de más de sesenta metros de alto, el líder argentino estaba imaginando una cultura moderna en la que el trabajo funcionara como índice de una ciudadanía disciplinada: desde las alturas y en pleno centro de Buenos Aires, ese cuerpo de arquitectura futurista podría ser contemplado por cualquier paseante y servir de guía para aquellos que podían perder el camino y desviarse de los destinos de la nación. Porque ese camino debía llevar a un solo sitio: el trabajo.

Los antecedentes de esta centralidad de la figura del proletario en el campo político argentino habría que buscarlos en la intensa industrialización y la llegada periódica a las grandes ciudades de una masa de inmigrantes durante las primeras décadas del siglo veinte. Fenómeno novedoso a partir del cual la fábrica y la oficina emergieron como motores para incorporar esas masas extrañas a la ciudadanía: el intimidante forastero que llegaba a la ciudad desde el interior del país o desde un país extranjero se convertía a partir de su lugar en el aparato de producción en un "obrero", en un "oficinista", o directamente en un proletario.

El trabajo se convirtió entonces en un poderoso mecanismo para asignar una identidad y nacionalizar a esos sujetos. Este novedoso proceso no fue, sin embargo, un rayo en un cielo despejado: la centralidad del trabajo como forma de nacionalizar a la ciudadanía representó un cambio de paradigma pero también una continuidad frente a otros modelos de nacionalización. Desde finales del siglo XIX y a partir del afán estatal por capturar tierras y volverlas productivas, el ejército venía siendo la máquina de nacionalización por excelencia. Algo que se reforzaría con la llegada del nuevo siglo, cuando el servicio militar obligatorio se convirtió en la matriz estatal para institucionalizar a los ciudadanos. Recién con el

1 Así describe Ignacio Jawtuschenko el proyecto del "Monumento al Descamisado": "Un trabajador cuarenta y cinco metros más alto que la Estatua de la Libertad. Una base más grande que el Luna Park. Catorce ascensores. Un salón grecorromano con paredes de mármol, frisos y columnas. Una cúpula revestida de mosaicos con pepitas de oro. Una basílica laica. Y un sarcófago de cuatrocientos kilos de plata para albergar el cuerpo de Eva Perón", Ignacio Jawtuschenko sobre el proyecto del "Monumento al Descamisado" de Perón. En Jawtuschenko, Ignacio. Radar." Página/12 ,10 Oct. 2004. 
peronismo la figura del trabajador alza el pie y se sube al pedestal del ciudadano nacional. Y no es cualquier trabajador el que asume esa función. El proyecto del monumento al Descamisado da garantía de ello: trazado sobre el aporte involuntario de los enemigos políticos, el proletario de suburbio, arremangado y con el torso al descubierto, empujaba -como veremos- hacia la ruptura con el pasado oligárquico.

La centralidad que adquiere el proletariado durante el peronismo no debe obturar, sin embargo, otras cuestiones ligadas al rol del trabajo y el trabajador durante la primera mitad del siglo veinte. La representación del proletario es durante ese período un territorio de densas disputas que involucran a diferente actores sociales y que abren un amplio abanico de problemas, como la modernización del trabajo, la nacionalización de los sujetos y el disciplinamiento de los cuerpos. De hecho, uno de los peligros para el análisis consiste en recaer en una mirada evolutiva que postule al peronismo como una suerte de trascendencia o momento exterior en el que las contradicciones inherentes al mundo del trabajo encuentran una resolución ${ }^{2}$. Para ello, propongo un recorrido por diferentes momentos de la representación del trabajador durante la primera mitad del siglo veinte en Argentina, para indagar la forma en que una de sus corporalizaciones, el proletario urbano, fue adquiriendo una espesura conceptual y una presencia

${ }^{2}$ Agustín Nieto devela los peligros de una mirada madurativa en torno a la identidad de la clase obrera: "El punto de partida es la extrema heterogeneidad (inmadurez) que presenta la clase obrera, mientras que el punto de llegada es aquel que representa el grado más alto de homogeneidad (madurez) de clase. En términos político-ideológicos el proceso madurativo recorre, en su deriva marshalliana, del anarquismo al peronismo; mientras que en su deriva leninista-hobsbawmsiana, su proceso madurativo va de la conciencia primitiva pre-política anarquista o a una conciencia socialista (comunista). El orden en la secuencia puede variar, también la estación final, no así el esquema rector de la narración. Entre las distintas alternativas secuenciales una bastante representativa es aquella que en un primer tramo de la formación de la clase obrera de nuestro país ubica al anarquismo, en un segundo tramo al sindicalismo revolucionario, en un tercero al socialismo, en un cuarto al comunismo, finalizando en el peronismo como corriente ideológico-política hegemónica en el mundo obrero. En esta última estación el proceso marshalliano de ciudadanización se ve consumado", en Nieto, Agustín. "Herramienta Debate Y Crítica Marxista". Narrativas Sobre La Historia Obrera En Argentina: Notas Críticas Y Apostillas Conceptuales. "Revista Herramienta". 18 Mar. 2016. 
CATEDRAL TOMADA: Revista de crítica literaria latinoamericana / Journal of Latin American Literary Criticism Monumentos, monstruos y espectros: la figura del proletario en Argentina (1920-1950)

ineludible en los debates político-culturales en torno a la configuración de lo nacional.

Más aún, analizaré la forma en que la propia representación del proletariado argentino se convirtió en un objeto de disputa. Interpelado tanto desde las proto culturas de izquierda que surgieron en la década del veinte (puntualmente, la revista Claridad o los experimentos culturales llevados a cabo por Castelnuovo), como desde ese otro tipo de pedagogía estatal para la nacionalización de las masas (que aparece condensado en el monumento al descamisado), el proletariado se fue perfilando como un significante vacío: por una lado, como ansiedad de condensación, de síntesis (en términos de una autonomía que intentará ser interceptada, abordada por diversos proyectos políticos, culturales o artísticos) y, por otro, como inestabilidad de sentido, como figura que no puede concretarse porque aparece recurrentemente atravesada por una heterogeneidad que le es inherente y que la desestabiliza. Entre la normativización y la resistencia, la figura del proletario adquirió, entonces, una centralidad inédita.

El arco temporal que propongo va desde la irrupción de las masas ${ }^{3}$ durante las primeras décadas del siglo veinte hasta el derrocamiento de Perón en 1955. A partir del análisis de un un contexto cultural espeso que incluye elementos

${ }^{3}$ Seguimos aquí la distinción entre masa y pueblo propuesta por Montaldo: "Un recorrido histórico por la idea de masa, nos llevará a identificar normalmente a un sujeto sin rostro, que actúa en la impunidad del anonimato; en estas características se sostienen todas las reflexiones sobre la masa. Como tal, no se identifica ni con una clase social, ni con un grupo político, no la deslinda una determinación ideológica ni un tipo particular de formación cultural, pero tampoco el número de los individuos que entran en su constitución. Sin embargo, ha sido definida desde la cultura, la clase, la relación con la ley y con el número. Los nombres de chusma, populacho, turba, plebe, son frecuentes, pero también lo han sido los de 'clases peligrosas' y 'bárbaros'. Esta dispersión nominativa hará que sean los nombres quienes decidan la suerte de los sujetos que designan. Como fenómeno se hace excesivamente visible en el siglo XVIII y en Europa; allí adopta una entidad que no es solo problemática sino que comienza a ser una preocupación generalizada de las elites modernas que, a la vez que promueven el ingreso de nuevos sectores a la comunidad política, se sienten amenazadas por ellos". En Montaldo, Graciela. "La Desigualdad de las Partes", Peluffo, Ana. Pensar El Siglo XIX Desde El Siglo XXI: Nuevas Miradas Y Lecturas. p. 31 
heterogéneos (discursos políticos, intervenciones intelectuales, revistas culturales de la izquierda emergente como "Los Pensadores" y "Claridad", y la ya mencionada iconografía), en este texto indago dos problemáticas que suelen aparecer entrelazadas pero que intentaré diferenciar: por un lado, la modernización del trabajo $\mathrm{y}$, por otro, la nacionalización de cuerpos/subjetividades. En otras palabras, exploro los mecanismos que -ya sea desde el Estado o desde esas proto culturas de izquierda que estaban surgiendo en Argentina con el auge del anarquismo y el socialismo-, se utilizaron para hacer de las masas que llegaban a la ciudad un conjunto de trabajadores disciplinados, modernos y nacionales para la producción y, al mismo tiempo, y sus respectivas formas de resistencia.

\section{“Escándalo en el zaguán”: el ciudadano y el trabajador definidos desde la cultura.}

En su célebre discurso del 17 de octubre de 1945, Perón se dirige a las masas que habían copado la Plaza de Mayo y aclara abiertamente dónde había que buscar al futuro ciudadano nacional. Dice:

Hace hoy casi dos años que desde estos mismos balcones dije que tenía tres honras en mi vida: la de ser soldado, la de ser un patriota y la de ser el primer trabajador argentino. En la tarde de hoy el Poder Ejecutivo ha acordado mi solicitud de retiro del servicio activo del Ejército [...] Guardo el honroso y sagrado uniforme que me entregó la Patria para vestir la casaca de civil y confundirme con esa masa sufriente y sudorosa que elabora la grandeza de la Patria. Con esto doy un abrazo final a esa Institución que es el puntal de la Patria: el Ejército. Y doy también el primer abrazo a esta masa grandiosa que representa la síntesis de un 
CATEDRAL TOMADA: Revista de crítica literaria latinoamericana / Journal of Latin American Literary Criticism Monumentos, monstruos y espectros: la figura del proletario en Argentina (1920-1950)

sentimiento que había muerto en la República: la verdadera civilidad del pueblo argentino.

Si desde el siglo XIX el Estado argentino se había encargado de instalar la figura del militar en la trama urbana como una forma de articular la comunicación entre los individuos frente a la presencia intimidatoria de un "otro" exterior y peligroso, para mediados del siglo $\mathrm{XX}$ el trabajador del peronismo viene a cuestionar esa preponderancia del soldado en el imaginario del ciudadano ideal. Y lo cuestiona fundamentalmente porque el motivo de lo militar llevaba adosado toda una genealogía de clase bien definida: en la historia cultural argentina el soldado/militar tendió a ser patrimonio de las élites. Algo que queda muy claro en la operación que Borges propone recurrentemente sobre el mundo idealizado de sus antepasados: los mayores, los fundadores, los guerreros, el linaje de sangre ${ }^{4}$. Un panteón hermético al que solo se accede por el prestigio de la herencia.

Con el peronismo, en cambio, se abre otra genealogía ligada ya no a las élites sino a los cuadros medios, y basada en la propia autobiografía del líder. Si Perón se autodefine recurrentemente como "el primer trabajador", esta nueva genealogía, fundada por y a través del dirigente, autoriza la preponderancia del trabajo y fija un nuevo modelo de ciudadanía. El verdadero ciudadano argentino no se halla ahora en las gestas militares: como reclama en su discurso, la auténtica civilidad del pueblo argentino habría que buscarla en "la masa sufriente y sudorosa". O, mejor, en las masas trabajadoras.

${ }^{4}$ Como dice Ricardo Piglia, la escritura de Borges se construye en el movimiento de reconocerse en un linaje doble: "Por un lado los antepasados familiares [...]: 'Esta vana madeja de calles que repiten los pretéritos nombres de mi sangre: Laprida, Cabrera, Soler, Suárez. Nombres en que retumban (ya secretas) las dianas, las repúblicas, los caballos y las mañanas, las fechas, las victorias, las muertes militareś. Por otro lado, la investigación de los antepasados literarios, los precursores, los modelos, el reconocimiento de los nombres que organizan el linaje literario". Piglia, Ricardo. "Los dos linajes", en Ficciones Argentinas: antología de lecturas críticas. Grupo de investigación de literatura argentina de la UBA, compilador. Buenos Aires: Norma, 2004, p. 36 
Pero no solo se trata de una crítica al militarismo. Esta postura implicaba también un claro cuestionamiento a la concepción propia de las élites tradicionales que, como veremos más adelante con la formulación de Rodó, pretendía que el ciudadano verdaderamente auténtico y nacional se definía a partir del ocio de clase. La consigna peronista de que "cada argentino debe producir por lo menos lo que consume" viene a invertir el lugar que ocupan las élites en el imaginario nacional. Si los ciudadanos son los que producen, los sectores ociosos pasan a ser los "otros" de la Nación. Suele decirse que toda revolución modela su propia galería de héroes. Cabe agregar que todo paradigma de nacionalidad se construye a partir de la otredad: ¿quién es el otro de la nación? ¿quién ocupa esa extranjeridad? La integración de un sujeto colectivo supone siempre la neutralización de ese otro que va en contra de los verdaderos intereses de la patria. Solo tras delimitar ese espacio abyecto se puede definir un "nosotros" 5 . O, en otras palabras, el lugar de los propios.

Ese mismo lugar que Perón le había asignado al trabajo en su discurso será ratificado con su proyecto del monumento al descamisado que mencioné al comienzo de este artículo. Sin embargo, esa centralidad que adquiere la producción durante el peronismo es el desenlace de un largo proceso ¿Qué es lo que había cambiado para que el trabajo desplazara la primacía del ejército en tanto mecanismo de nacionalización de los sujetos? Una de las causas habría que buscarla en la llegada de una nueva oleada inmigratoria, principalmente urbana, durante finales del siglo XIX y las primeras décadas del XX. La magnitud quedó retratada en los resultados que arrojó el censo de 1914 al poner de manifiesto la existencia de "una población de 7.885.000 habitantes, de los cuales alrededor del $50 \%$ eran extranjeros. Una cultura criolla de carácter fundamentalmente rural que comenzaba a extenderse hacia la urbe se superpuso y fusionó con los estilos de vida de una multitud de inmigrantes europeos que llegaban al país atraídos por el

\footnotetext{
${ }^{5}$ En esta dirección, el peronismo llega, incluso, a animalizar a las clases acomodadas que pasan a ser concebidas en tanto parásito de la clase trabajadora. El ocio de clase y su parasitismo es lo que debilita el pretendido andar victorioso de la patria. El sujeto nacional hay que buscarlo en los que trabajan; aquellos que los rodean, en cambio, empiezan a ser definidos como simples parias.
} 
CATEDRAL Tomada: Revista de crítica literaria latinoamericana / Journal of Latin American Literary Criticism Monumentos, monstruos y espectros: la figura del proletario en Argentina (1920-1950)

proyecto industrializador emprendido por el Estado"6. El problema comenzaba a desplazarse del campo a la ciudad: si la anterior llegada masiva de inmigrantes había convocado el problema de la ocupación del espacio rural a través de la máquina de guerra (el "gobernar es poblar" de Alberdi), la preocupación de las élites respecto de esta nueva oleada pasará por la disciplina por el trabajo y la civilidad en la ciudad.

Las mismas élites que habían promovido el ingreso de nuevos sectores a la comunidad política, se sintieron, as su vez, amenazadas por ellos. Refiriéndose al carácter "aluvial"7 de la inmigración, anota José Luis Romero: "Se dibujó en la conciencia de la élite la imagen de unas masas torvas y oscuras, desligadas de todo vínculo, peligrosas, que acechaban en las sombras y que estaban empezando a invadir los ámbitos hasta entonces reservados a los hijos de la patria” (30). La cita marca un contrapunto entre, por un lado, esos "hijos de la patria", auténticos interlocutores del Estado y, por otro, la masa, "en tanto presencia que siempre viene a desbaratar, poner en cuestión, impedir, tergiversar" ${ }^{8}$. Esa entidad "torva y oscura", como la califica Romero, siempre indica un plural descontrolado, un peligro en ciernes, una amenaza de violencia.

Desde el punto de vista de las élites nacionales, los nuevos "enemigos sociales" eran aquellos que, previa inclusión en el campo social, sufrieron la

${ }^{6}$ Gloria Beatriz Chicote, Mariana Masera. "La presencia de la Literatura Infantil Juvenil en los impresos populares iberoamericanos de principios del siglo XX: el caso argentino" en Cañamares, Cristina, Luján Atienza Ángel Luis, and César Sánchez Ortiz.Odres Nuevos: Retos Y Futuro De La Literatura Popular Infantil. Cuenca: Ediciones De La Universidad De Castilla-La Mancha, 2016, p. 324

${ }^{7}$ Con este término, José Luis Romero alude a la afluencia de elementos que proceden de diferentes sitios y no se acomodan entre si. Es una imagen que condensa el cambio y la velocidad en diferentes ámbitos: por un lado, la alteración demográfica y étnica, y, por el otro, los cambios económicos.

${ }^{8}$ Aquello que Montaldo identifica como "pueblo": un significante cuyo referente "no es preciso en el sentido de que se arma sobre categorías legales -ciudadanía- pero también afectivas -quienes responden a la patria, a la nación, cualquiera sea su llamado: 'Pueblo' se usa para nombrar a aquel colectivo que se reconoce como aliado y con el cual se cuenta para definir el pacto político", en Montaldo, Graciela, p. 32 
exclusión de maneras diversas ${ }^{9}$. Ahora, como se pregunta Raúl García en Micropoliticas del cuerpo, ¿cuál era la necesidad de incluir? O, mejor: ¿por qué no dejar afuera del acuerdo social directamente a aquellos que se consideraba potenciales enemigos del mismo? ¿qué sentido tenía el acuerdo con "los intolerables”? "El fundamento de esta operación inclusiva habría que buscarlo en que el enemigo está mejor controlado cuando se posee mayor información constante y confiable sobre él" (95). Justamente, desde finales del siglo XIX, dos de los más significativos intelectuales argentinos venían intervenido activamente en esta cuestión. Tanto Ramos Mejía como Miguel Cané teorizaron sobre la necesidad de incorporar al trabajador inmigrante para la patria naciente, advirtiendo sin embargo sobre los peligros de determinado tipo de trabajador. En ambos casos, esas advertencias se tradujeron en leyes y políticas estatales concretas: la legislación propuesta por Miguel Cané, ante el avance del anarquismo se tradujo en la promulgación por la Ley de Residencia, que permitía la expulsión de aquellos inmigrantes "cuya conducta pueda comprometer la seguridad nacional, turbar el orden público o la tranquilidad social”. La acción de Ramos Mejía, por su parte, consistió en el diseño de la Policía Industrial, cuerpo que obtendría un papel preponderante en la recolección de información de los ámbitos obreros, de extrema utilidad para pergeñar tácticas de control e intervención sobre el mundo del trabajo. De esta forma, la figura del proletario cargaría con la nueva amenaza social, ideológica, a través de las organizaciones obreras y los movimientos anarco-socialistas ${ }^{10}$.

\footnotetext{
${ }^{9}$ Vale aclarar que esta disputa tiene antecedentes culturales densos. Con la victoria de Yrigoyen consumada (lo que implicaría la puesta en marcha de un proceso de industrialización y de la incorporación de las masas al proceso de producción), las élites procuraron renovar los signos de pertenencia de una población en conflicto. Entre la inmigración extranjera y las migraciones internas, dominaba la ausencia de una adhesión generalizada al campo simbólico nacional. La amenaza al orden social pasaba principalmente por el anarquismo y el socialismo que pretendían nuclear a los trabajadores a partir de pedagogías alternativas a las provenientes del Estado.

${ }^{10}$ En esta misma línea, Ramos Mejía dirigió también el Consejo Nacional de Educación y la creación de una liturgia patria con el fin de nacionalizar a los hijos de extranjeros.
} 
CATEDRAL TOMADA: Revista de crítica literaria latinoamericana / Journal of Latin American Literary Criticism Monumentos, monstruos y espectros: la figura del proletario en Argentina (1920-1950)

Si el Estado respondió activamente (tanto con sus aparatos ideológico como con los represivos $)^{11}$ frente a la amenaza que suponía la organización de los trabajadores, la cultura no fue un agente menor en esta disputa. Una de las tesis centrales de Crítica acéfala de Raúl Antelo revela hasta qué punto las categorías de trabajo, cultura y política aparecen implicadas en la figuración del ser nacional. De acuerdo con Antelo,

el gran tema de la primera mitad del siglo XX de la cultura letrada en América Latina, consiste en asociar el músculo al intelecto [...] ¿cómo alterar las estructuras políticas de compromisos y alianzas con `los de abajo', sin afectar por ello la eficiente redistribución simbólica moderna? (Antelo 34)

Si en la cita de Romero la relación de las élites con las masas se articulaba a partir de lo racial (o lo demográfico: "las masas torvas y oscuras"), lo novedoso de la propuesta de Antelo pasa por la apelación a toda esa serie de revistas culturales y proyectos de izquierda (esas proto culturas proletarias) que estaban emergiendo en la Argentina de principios de siglo. Tal como aparece en la cita, las masas ("los de abajo") son ahora "el músculo", la mera corporalidad o fuerza que debe ser asistida por un dirección superior ("el intelecto"). Antelo pone en funcionamiento un innovador dispositivo a partir del cual la masa aparece ya atravesada por el disciplinamiento y convertida en fuerza de trabajo. Se trata de diferentes lógicas que atraviesan los cuerpos y las convierten en objetos legibles para las élites; una tensión entre, por un lado, concebir a la masa como una entidad peligrosa y escurridiza, y, por el otro, articularla como fuerza de producción.

${ }^{11}$ Basta mencionar la llamada "Semana Trágica", conflicto que se originó en una huelga en Talleres Vasena a principios de 1919 y que dejó alrededor de 700 muertos. 
Es más, el ejemplo que pone Antelo para graficar esta relación entre el músculo e intelecto, es la obra de Lugones. Desde esta óptica, la construcción en torno al gaucho erigida por el poeta argentino, aparece como uno de los momentos culturales centrales en lo que respecta a la articulación de las masas en un proyecto nacional. De hecho, el mismo año en que Lugones se refiere a "la plebe ultramarina que arma escándalo en el zaguán” -para aludir a las protestas de los trabajadores nucleados principalmente por el anarco socialismo-, se publican sus seis conferencias sobre el Martín Fierro, reunidas bajo el sugestivo título de "El payador" (1916). La sincronía entre la cita y la publicación es relevante porque ese texto se articularía como un programa cultural en el que se sentaron las bases simbólicas para una identidad nacional, frente a aquello que era percibido como peligroso por las élites. A través del arquetipo mítico del gaucho y de la exaltación de determinados valores telúricos, Lugones construyó un patrón de vida ejemplar, digno de ser imitado por los miembro de la comunidad. Lo curioso es que si el gaucho lugoniano está dotado de una serie de cualidades que lo convierten en un ser excepcional, una de las características decisivas es justamente aquella que le da nombre al libro: el ciudadano ideal lugoniano es básicamente un "payador", un poeta que "vivía de su guitarra y de sus versos" (Lugones 53).

Desde esta lectura, el gaucho deja de ser un peón rural en el sentido estrictamente material y en su relación decisiva con la palabra se articula su alejamiento del mundo de la producción. Lugones invisibiliza el trabajo y como corolario de esta producción teórica-poética, el prototipo que el escritor argentino propone para encarnar el ser nacional no será ni el trabajador urbano ni el peón rural: "En Lugones, la figura del gaucho va adquiriendo una composición cada vez más fantasiosa. Ni el gaucho histórico -el gaucho como peón rural- ni el obrero inmigrante: la construcción intelectual de Lugones se inclina progresivamente por el mito" (27), dice Edgardo Dobry. El payador se ha convertido en símbolo de un humanidad plena, cargada de valores pero, a su vez, en una entidad etérea, vaciada de toda corporalidad y ajena al mundo del trabajo. 
CATEDRAL TOMADA: Revista de crítica literaria latinoamericana / Journal of Latin American Literary Criticism Monumentos, monstruos y espectros: la figura del proletario en Argentina (1920-1950)

En esta misma línea, un texto fundamental del canon latinoamericano como lo es Ariel de Rodó, había vinculado ya la "cultura" con un tipo específico de facultades intelectuales, "espirituales", “desinteresadas", en plena antítesis con el utilitarismo de la vida económica y la figura clásica del trabajador manual. En el texto de Rodo, el discurso de Próspero se dirige a los jóvenes que son concebidos como la "fuerza" y lo "activo". Sin embargo, esa fuerza juvenil no estará destinada a producir en el sentido material. Por el contrario, la función de estos jóvenes en la sociedad se corresponde, según Rodó, con el “ocio creador”, el pensamiento o el discurso:

Un rayo del moribundo Sol atravesaba la estancia, en medio de discreta penumbra, y tocando la frente de bronce de la estatua, parecía animar en los altivos ojos de Ariel la chispa inquieta de la vida. Prolongándose luego, el rayo hacía pensar en una larga mirada que el genio, prisionero en el bronce, enviase sobre el grupo juvenil que se alejaba. (37)

La cultura será, entonces, el territorio de Ariel quien contrapuesto a Calibán, ese monstruo que simboliza la "sensualidad y de torpeza", se opone ya a la "barbarie irruptora" de la masa urbana. Ante esa amenaza, la intención de Rodó consiste en convertir a la sociedad latinoamericana en un espacio homogéneo y legible para las élites a través de un proyecto que distribuya al intelectual (aquel escogido para la creación y al uso del discurso) y al resto de los trabajadores (aquellos destinados a tareas materiales) en esferas separadas ${ }^{12}$.

En ese texto las élites habían encontrado su propia iconografía: el bronce de Ariel festejado en los textos de Rodó servía como reflejo celebratorio de las

\footnotetext{
12 Esta dicotomía sería recuperada y modificada varias décadas más adelante por Fernández Retamar en Calibán (1971). En alguna medida, el cambio en la perspectiva y en la valoración de este personaje (pasa a ser valorado positivamente en tanto encarnación de lo latinoamericano) puede relacionarse con la nueva coyuntura: en la década del setenta, el objetivo para Retamar ya no pasa por la modernización sino por la descolonización. Retamar no pretende estar por delante de las multitudes -como sí pretendía Rodó-, sino detrás del proletariado.
} 
clases hegemónicas. Medio siglo después del nacimiento del arielismo, las disputas por la representación del ciudadano ideal abandonaban aquel cuarto de estudio -desde el que teorizaba Próspero- y se desplazaban hacia el centro de la ciudad. Como en un holograma, el busto de Ariel se recorta contra el monumento proyectado por Perón. En este montaje espacial y temporal se enfatizan las diferencias: si la estatua de Ariel encarna el ideal del pedagogo como mecanismo de nacionalización o control de la clase dirigente, la apuesta por la gigantografía del proletario es otro momento de esa pedagogía que apela principalmente a lo corporal: el "Descamisado", por sus dimensiones y su énfasis en lo corpóreo, se perfilaba entonces como una entidad expansiva, altamente democratizadora. El cuerpo del obrero concebido por el peronismo pretendía abrirse como una alameda para la inclusión de las masas a la nación. Así, el supremo anhelo de convertirse en mármol, lograr la belleza perenne y firme de la estatua de Ariel era interrumpido por esta presencia monstruosa, los casi setenta metros de un obrero de suburbio con el torso al descubierto. El proletario con toda su rusticidad salía a la calle y amenazaba con invadir el centro de la ciudad ${ }^{13}$. El violento golpe de estado del '55 contra el peronismo y su consiguiente proscripción intentarían impedirlo.

${ }^{13}$ Desde ya que uno de los alusiones literarias a este fenómeno es el texto "La fiesta del Monstruo", de Borges y Bioy Casares. La visibilización y barbarización de los sectores populares en su acceso al centro de la ciudad son algunas de las claves del relato. 
CATEDRAL TOMADA: Revista de crítica literaria latinoamericana / Journal of Latin American Literary Criticism Monumentos, monstruos y espectros: la figura del proletario en Argentina (1920-1950)

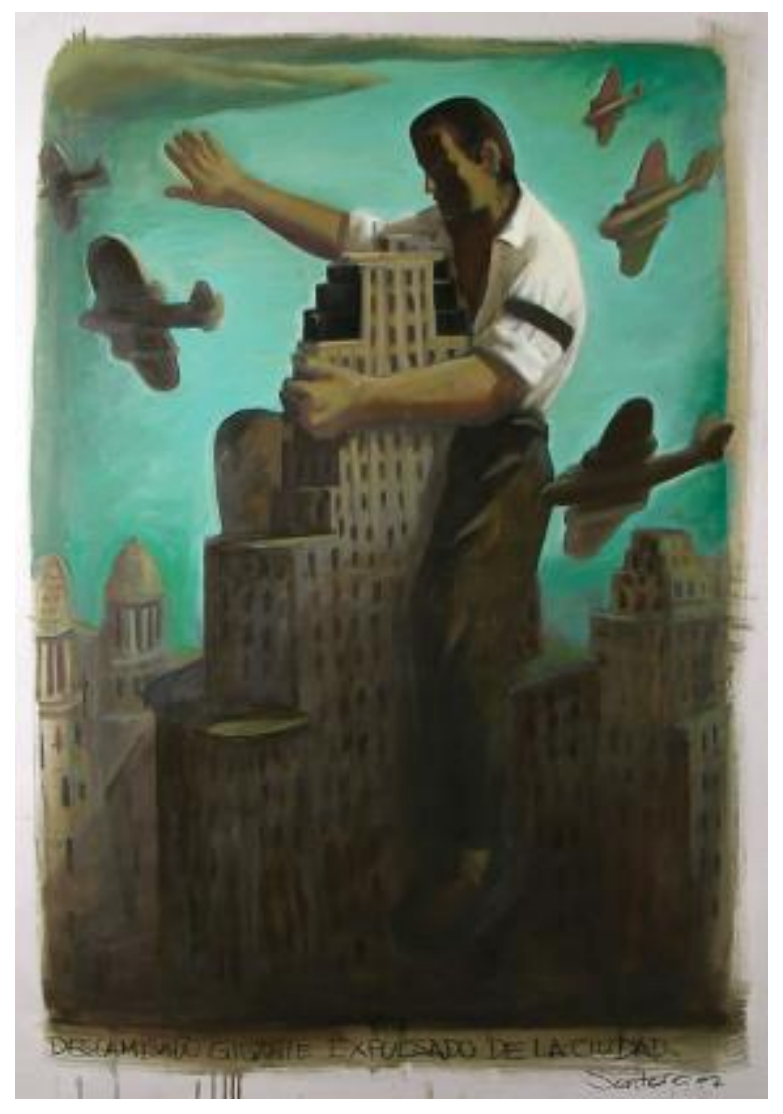

Ilustración 2.Daniel Santoro. "El descamisado gigante expulsado de la ciudad”. Óleo140 x 90 cm, 2008.

\section{(In)Disciplinas: Monstruos, espectros, rechazos.}

En una reportaje de 1980 con la revista "Lecturas críticas", Osvaldo Lamborghini reconoce que el enemigo de la revista Literal (que él mismo publicaba con Germán García) podía ser identificado fácilmente:

¿Querés que te diga la verdad? ¿Cuál es el gran enemigo? Es González Tuñón; los albañiles que se caen de los andamios, toda esa sanata, la cosa llorona, bolche, quejosa, de lamentarse [...]. Esto es poesía quejosa, hacer esta especie de orgullo de padre proletario, que se levantaba a las cinco 
de la mañana con sus manos callosas; que traía pan crocante a la mesa... [...]. No hay, te digo, una cosa personal con Castelnuovo, más bien con la ideología liberal de izquierda, esa cosa llorosa. Es decir, que los escritos tienen que valer por el sufrimiento que venden y por las causas nobles de ese sufrimiento. (48)

El testimonio de Lamborgini devela hasta qué punto la producción del grupo de Boedo en torno al mundo del trabajo había logrado instalarse en el campo cultural argentino a lo largo del siglo veinte. Desde esta perspectiva y a partir de la apelación "llorona" y "quejosa" a "los albañiles" o al "padre proletario" de "manos callosas", González Tuñon y Castelnuovo exceden al propio boedismo -en tanto corriente con preferencia por temas y tópicos del imaginario proletario- para aparecer como la personificación de la propia ideología liberal de izquierda. El mundo del trabajo era presentado desde una visión pietista y era esa misma piedad lo que fomentaría la reacción de los lectores. De allí que González Tuñon y Castelnuovo vehiculizaran para el autor de "El niño proletario" aquello que la nueva literatura debía evitar.

En cualquier caso, lo que está por detrás del testimonio de Lamborghini es la división que marca el campo cultural argentino de las décadas del veinte y el treinta, entre Florida y Boedo. La inmigración y el cosmopolitismo fueron las puntas de lanza de ese enfrentamiento: si la tradición que va de Lugones al grupo de Florida insistió en fundamentar una identidad argentina futura encarnada en la promoción de valores arraigados en el pasado y condensada específicamente en la figura del gaucho, la vinculación de intelectuales boedistas con las masas de trabajadores tiene como antecedente fundamental la revolución rusa ${ }^{14}$. Como dice Elías Castelnuovo en Memorias: "la batalla entre Boedo y Florida se inició sin previo aviso [...]. Mientras Florida sostenía que a nuevos tiempos correspondían

\footnotetext{
${ }^{14}$ De acuerdo con Sarlo, en Argentina la referencia a los hechos de Octubre es tan poderosa "como para provocar un poema de Borges".
} 
CATEDRAL TOMADA: Revista de crítica literaria latinoamericana / Journal of Latin American Literary Criticism Monumentos, monstruos y espectros: la figura del proletario en Argentina (1920-1950)

nuevas formas de arte, Boedo sostenía que a nuevos tiempos correspondían nuevas formas de vida" (125).

Más allá de este énfasis en el vitalismo en desmedro de las "formas de arte", esas "nuevas formas de vida" necesitarían también una nueva literatura. Al menos esa era la opinión del propio Castelnuovo quien subraya que en Boedo se inauguró la literatura proletaria "cuando todavía nadie hablaba de ella". Esa literatura, aclara, no consideraba al proletariado argentino como una clase en pugna con la nación, sino con otras clases sociales. Concluye que "las masas laboriosas venían a ser, en definitiva, las depositarias del destino de la argentinidad" (128). Así, el lugar de los trabajadores en esta alegoría nacional articulada por Castelnuovo es el de una nueva clase social juvenilizada, una novedad generacional que coincidirá con una novedad de clase. Aquí no se menciona al gaucho como ideal: es a las masas urbanas a las que les corresponde el destino de la argentinidad. No se trata tanto de una propuesta que contempla la asimilación del proletario al Estado como de una apuesta a que los cambios políticos llegarían desde los propios trabajadores.

Allí estaba el futuro. Y Boedo pretende ir a su encuentro. En 1929, la editorial Claridad ${ }^{15}$, ámbito de difusión de la Escuela de Boedo, lanza Ateneo Claridad, un nuevo órgano que se propone reproducir, reflejar y debatir "la hora actual de la civilización". Se presenta como una agrupación de "amigos" que apoyará a los gremios, intervendrá en movimientos sociales, ideológicos, artísticos o científicos "sin adquirir por ello carácter de agrupación política". En el número que ese año le dedica al día del trabajador, el grupo publica una carta de propósitos con una serie de puntos vinculados a su radio de acción. Destaco uno de ellos: "XIII. Organizará visitas y excursiones a museos de arte y ciencias, a talleres, a fábricas o industrias, etc. procurando que a a ellas asista una persona técnica que ilustre objetivamente a los concurrentes"16. La cita resulta relevante

15 El primer número de la "Revista Claridad" salió el 23 de julio de 1926 y se extendió regularmente hasta diciembre de 1941.

16 “Ateneo Claridad: propósitos”. Claridad. N 181, Buenos Aires, 27 de abril de 1929 
no solo para pensar el lugar particular en el que pretende instalarse la revista Claridad -editorial pionera en la articulación trabajo/literatura en Argentina y cuyas prerrogativas, como decía Lamborghini, se instalaron en una tradición que excede con mucho el mundo literario-, sino también para dar cuenta del acecho de las diferentes miradas de las que fueron objeto la fábrica y sus trabajadores durante las primeras décadas del siglo. Tanto la prensa gremial como los programas políticos, tanto el cine como la publicidad (entre otros discursos), abordaron desde diferentes perspectivas el novedoso -y muchas veces herméticomundo de las fábricas. En esta dirección, cuando la editorial Claridad se jacta de organizar visitas y excursiones "a talleres, a fábricas o industrias, etc. procurando que a a ellas asista una persona técnica que ilustre objetivamente a los concurrentes", se autopostula justamente como una mirada capaz de penetrar en ese ámbito cerrado, abrir esa caja y darla a conocer a otros sectores de la población. Claridad se ofrece, entonces, como un puente entre los diferentes estratos de la sociedad, como una mediación de clases.

Más allá de esta pretensión por ir al encuentro de los trabajadores, la propia figura del proletario no era fácil de identificar. Como veremos, el proletariado no es solo la cifra de una ansiedad sino que su identificación se vuelve una necesidad. En este sentido, una de las claves de este artículo consiste en cotejar la relación entre la industrialización precaria, sinuosa y periférica de la Argentina con la inestabilidad inherente a la representación misma del proletario. En un texto del '55, Realismo y Realidad en la literatura argentina, Portantiero revisa las tesis del boedismo y dice que si bien en ese movimiento hay una auténtica fuerza narrativa, por otro lado domina "una visión retórica de la realidad que es justamente lo que se postuló como literatura proletaria". De acuerdo con Portantiero, la causa de esa visión retórica de la realidad consiste en que no podía existir una identidad con aquello que debería ser una literatura proletaria por el simple hecho de que en Argentina no existía un proletariado como tal: no se dispone de algo así como un "proletario objetivo", sino que se trata de algo en 
CATEDRAL TOMADA: Revista de crítica literaria latinoamericana / Journal of Latin American Literary Criticism Monumentos, monstruos y espectros: la figura del proletario en Argentina (1920-1950)

pleno proceso de conformación. Es justamente la identidad con ese ente fantasmal lo que, según Portantiero, deviene en retórica.

Ansiedad de condensación, necesidad de síntesis, por un lado, e inestabilidad de sentido, por el otro. Frente a este contexto de limitaciones pero también de posibilidades, lo que se pone en juego son los procesos de subjetivación de una realidad en movimiento. La revista Claridad es un ejemplo paradigmático. La pedagogía se afianzó a lo largo de los quince años de su publicación como el motor para generar esa proximidad de clases ${ }^{17}$. Sin embargo, cuando ese programa teórico entre intelectuales y trabajadores (postulado como un camino despejado) es llevado a la práctica, aparecen algunos inconvenientes. Cierta reticencia por parte del mundo del trabajo parece salirse del plan inicial, y el proyecto del cuerpo social completo amenaza con no concretarse. Esto es lo que detecta Demetrio Buira en un editorial del 28 de abril de 1928. Para celebrar algo sombríamente- el día de los trabajadores, observa sin ningún tipo de rodeos que:

Si nos fuera posible disponer de la atención de los trabajadores y disciplinar su cerebro para el estudio de los problemas que les planteamos diariamente sería incuestionable el éxito de su liberación social y económica. Pero desgraciadamente no sucede así. Nuestra prédica no les llega con la eficacia que anhelamos y ello obedece un poco a su propia incapacidad y otro poco a la apatía e indiferencia que les domina [...] Hacemos lo posible por llegarles tanto al corazón como a

\footnotetext{
${ }^{17}$ Como afirma Graciela Montaldo, "la enseñanza se postula como la forma de unir dos sectores que se perciben como absolutamente distanciados pero que es posible acercar (...) ya la sola experiencia del contacto material con estas revistas (Claridad y Los Pensadores) produce la idea de un cuerpo absolutamente compacto donde no quedan espacios en blanco, donde nada puede filtrarse; la masa del texto parece desbordar los límites de la página tal como los editores deseaban que se derramara el sentido por los intersticios del tejido social". De hecho, aparecen recurrentemente las figuras del "músculo" y el "cerebro" (como metáforas de los trabajadores y los intelectuales), postulando como ideal de la enseñanza la creación de un cuerpo completo en el que uno y otro órgano se potencien mutuamente. Ese "cuerpo" completo es el que le daría paso a la sociedad socialista y la revista, como decíamos, aparece como un puente que se tiende entre ambos. En Montaldo, Graciela. "La literatura como pedagogía, el escritor como modelo". Cuadernos Hispanoamericanos, núm. 445 (julio 1987), Madrid: Instituto de Cooperación Iberoamericana, pp.40-64.
} 
la inteligencia con nuestra labor diaria, pero ellos se manifiestan cada vez más indiferentes y no ocupan su puesto que le corresponde en el gran ejército por la causa social quelos (sic) anima ${ }^{18}$.

La incorporación del trabajador a este proyecto intelectual encuentra la resistencia del proletariado, ese mismo sujeto político que aparece como la alternativa para la emancipación social. O, en términos de Castelnuovo, como el depositario del destino de la argentinidad. A diferencia de lo que ocurre con el ciudadano soldado (que es incorporado a la lógica estatal), la ansiedad de condensación o de síntesis que rodea al proletariado es repetidamente aplazada, postergada. Frente a los recurrentes intentos por asignarle una forma e incorporarlo a distintos proyectos políticos/intelectuales, el rasgo diferencial de este ese sujeto político pasa más bien por la falta de sometimiento.

El propio monumento al Descamisado que mencioné anteriormente da testimonio de este escenario. La estatua al trabajador planificada por Perón debía ser de unas proporciones tal que no pudiera pasar desapercibida para ningún habitante de la ciudad. Sin embargo, la obra dedicada al Descamisado nunca llegó a concretarse. Existen los planos, existen fantasías en torno a su forma. Es más, se sabe que Evita desde la cama del hospital en que murió llegó a dar instrucciones para el proyecto. Y que el escultor designado, el italiano Tommasi, llevó personalmente una maqueta a la habitación de la enferma. Teñida con ribetes del mito de Pigmalión, la crónica recoge que, al verlo, Eva se mostró sorprendida: "Esto es maravilloso. Es genial -repetía persistentemente-, porque es grande y sencillo"19. Poco después de su muerte, la comisión encargada solicitó al artista que sustituyera al descamisado por la figura de la propia Eva Perón. Contrariado, el escultor retrucó que esa modificación le quitaría belleza al monumento, que la figura escultural de Eva Perón no debía tener las dimensiones colosales que

${ }^{18}$ Buira, Demetrio. "Por nuestro porvenir", Claridad. N 157, Buenos Aires, 28 de abril de 1928.

${ }^{19}$ Diario Democracia, Buenos Aires, 26 de julio de 1953, p. 8 
CATEDRAL Tomada: Revista de crítica literaria latinoamericana / Journal of Latin American Literary Criticism Monumentos, monstruos y espectros: la figura del proletario en Argentina (1920-1950)

asumía la figura del descamisado. Declaró, asimismo, que "el monumento a Evita, de formas gráciles y delicadas, exigía el mármol como materia prima”. Lo concreto es que la figura del cuerpo proletario permanece como un espectro en el centro de la ciudad. El obrero, aquel trabajador que a partir de la división social del trabajo está destinado al uso casi exclusivo de su cuerpo, paradójicamente carece de uno. Su figura monumental aparece confinada a una representación meramente abstracta. Lo que queda es la fantasía, ese tejido de sueños en torno a su cuerpo. Grande y sencillo, dice Eva. Ajeno a las formas gráciles y delicadas que exigirían el mármol, añade Tommasi. Todo lo que persiste pendula en estas frases.

En el destino del monumento repercute, sin embargo, una serie de disputas en torno a la representación del propio proletariado. A lo largo de las primeras décadas del siglo veinte este sujeto colectivo que es convocado desde diferentes proyectos políticos/culturales aparece como un ente escurridizo, sin una figura definida. Entre los intentos de ser moldeado para usos estratégicos y sus respectivas negaciones, el proletariado fluctúa en un espacio intermedio. Una buena parte de los inmigrantes que había llegado a la Argentina lo sabía muy bien: desde principio de siglo y a partir de la citada Ley de Residencia, el Estado impuso la identidad de "vagos", "delincuentes", "inmorales" a los trabajadores extranjeros. Una vez más: todo nosotros debe construir primero a sus otros. La irrupción del gobierno radical en 1916 había cambiado parcialmente esa ecuación. Si hasta ese entonces los trabajadores eran vistos por el propio Estado como un conjunto de personas con una relación privada con el empleador, es a partir del gobierno de Yrigoyen que el trabajador adquiere el carácter de "ciudadano", poseedores de derechos cívicos.

Ciudadano/proletario, ahí estaba una de las claves de la cuestión: entre la igualdad supuesta que conlleva pensar, por un lado, a los ciudadanos y, por otro, la relación privada desigual entre trabajador y patrón, se constituye el sujeto en un lugar intermedio. Respecto de la constitución de los propios sujetos políticos y la subjetivación política, Jacques Rancière afirma que: 
[...] un sujeto es alguien que no pertenece, un extraño, o más aún, alguien que está entremedio (in-between). Proletarios fue el nombre que se le dio a la gente que está junta en la medida en que está entremedio, esto es, entre varios nombres, categorías e identidades, entre humanidad e inhumanidad, ciudadanía y su negación, entre la categoría de un hombre que usa herramientas y la de un ser pensante y hablante. La subjetivación política es el planteamiento de la igualdad -o el manejo de un daño- por parte de gente que está junta en la medida que está entremedio. (58)

Este lugar intermedio -o relación entre sujetos políticos y subjetivación política-, es aludido en otro monumento al trabajador (este sí concretado) que desde 1927 habita el bajo de la ciudad de Buenos Aires: "Canto al trabajo", de Rogelio Yrurtia. La obra presenta dos partes en relación de continuidad. En la posterior, los miembros de una familia prototípica y nacionalizada (dos niños escoltados por otras dos figuras paternales) abren los brazos y asumen una posición contemplativa: observan y convocan, esperanzados, el futuro. El trabajo aludido en el título de la obra, es para ellos el motor del progreso. Es curiosa la conformación de los cuerpos monumentalizados: todos los miembros de la familia conservan los rasgos bien definidos, las facciones de sus rostros son claras y sus miradas resplandecientes se exhiben al espectador.

Otra escena pliega, en cambio, el monumento: un amasijo de cuerpos fundidos entre sí recorta una versión monstruosa de los trabajadores. Esa turba de individuos secunda a la familia prototípica y nacionalizada, y redobla su esfuerzo para empujar una roca. A diferencia de aquellos, estos cuerpos proletarios aparecen mezclados, entrelazados. Para el espectador resulta prácticamente imposible individualizarlos. Como anoté anteriormente, durante la primera mitad del siglo veinte, la representación del proletario es la cifra de una ansiedad. Y si hay una disputa por su contenido también la hay por su contorno: el proletariado, esa gente que está entremedio, asoma como un significante vacío, una estructura 
que no puede ser capturada porque su propia constitución aparece atravesada por una heterogeneidad que la desestabiliza. Más aún: los trabajadores del monumento ponen tanto esfuerzo en mover la roca como en evitar ser identificados. En gran parte, sus miradas se dirigen al piso. Lo curioso es que cuando la escultura ofrece finalmente un potencial cruce de miradas con el espectador, los propios trabajadores se tapan la cara. Literalmente, el proletario interrumpe la visión (y la potencial identificación) con sus propias manos. Como si el diagnóstico lanzado por Demetrio Buira respecto de la reticencia de los trabajadores a ser representados ("Hacemos lo posible por llegarles tanto al corazón como a la inteligencia con nuestra labor diaria, pero ellos se manifiestan cada vez más indiferentes y no ocupan su puesto que le corresponde en el gran ejército por la causa social quelos (sic) anima") hubiera sido puesto en escena: no solo es imposible para el espectador individualizar a los trabajadores sino que los propios proletarios de Yrurtia impiden ser identificados.

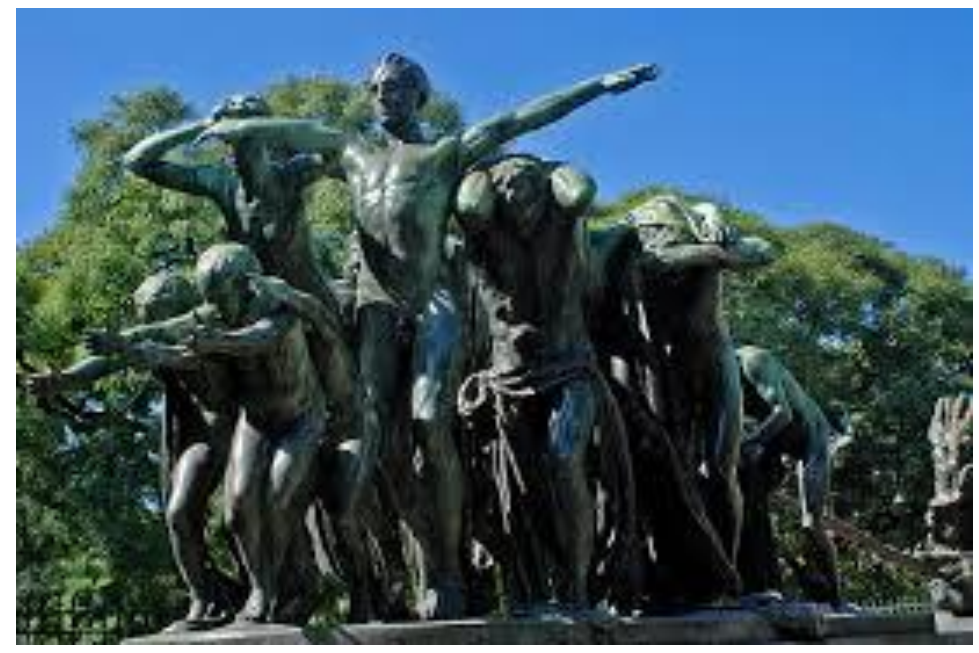

Ilustración 3. "Canto al Trabajo”, la escultura de Rogelio Yrurtia de 1927. 


\section{(In) disciplinas cosmopolitas}

La búsqueda de una referencia para la figura del trabajador se transformó en una urgencia para el campo cultural argentino de principios del siglo veinte. Portantiero diría que en ese período no se disponía de algo así como un "proletario objetivo" sino que se trataba de algo en pleno proceso de conformación. La intelectualidad argentina intentaría intervenir en ese proceso. Tanto las expresiones culturales asociadas a las élites como las proto culturas de izquierda insistieron en la normativización del proletariado: la revista Claridad pretendió armar una futuridad en torno al proletariado e inscribirlo en una línea teleológica que llevara a la revolución (Castelnuovo se había encargado de explicitarlo: las masas laboriosas eran las depositarias del destino de la argentinidad); Lugones, por su parte, pretendió barbarizar a los nuevos trabajadores urbanos.

Todas estas construcciones forman parte de la necesidad de conseguir una versión figurativa -sintética, terminada- del proletariado nacional. Sin embargo, una de las manifestaciones más claras a la hora de pensar en el proletariado como un significante vacío, es un experimento cultural llevado a cabo por el propio Castelnuovo $^{20}$. En el segundo número de la revista "Metrópolis", el escritor uruguayo anunciaba su inminente viaje a la Rusia soviética. Su propósito no residía en contar los preparativos del viaje o sus expectativas personales sino en destacar que "Entre las cosas que me llevaré de aquí, figura, en primer término, una colección de litografías, —obra de un artista nuestro: Guillermo Facio Hebequer $^{21}$-las cuales pienso exponer luego en Moscú y Leningrado”. Así

${ }^{20}$ Utilizo la categoría de experimento cultural en el sentido que le da Graciela Montaldo en Zona Ciegas. Populismos y experimentos culturales en Argentina. Más que la acepción típica de las prácticas científicas que se dirigen a confirmar premisas, la noción de experimento que pone en juego Montaldo pretende empujar la confrontación y exhibirla en su conflictividad.

${ }^{21}$ La agrupación "Artistas del pueblo" estaba conformada por Guillermo Facio Hebequer, José Arato, Adolfo Bellocq, Agustín Riganelli y Abraham Vigo. 
iniciaba una nota dedicada al artista en la cual lo definía como el Máximo Gorki de la pintura argentina, aunque también "se le podría llamar el pintor de los siete dolores. De los siete dolores sociales...", en tanto había recorrido "íntegramente la escala del infierno social”. Además, agrega sobre Hebequer:

Recuerdo que comenzó pintando el extremo de la cadena de los ex hombres: los pensionistas del manicomio. Su primera exposición estaba compuesta, casi exclusivamente, por una caravana aterradora de insanos que había reproducido directamente de un hospicio de alienados. Luego, fue degradando su visión pesimista, y nos presentó una muestra de atorrantes, también auténticos, que extrajo pacientemente de los recovecos más oscuros de la metrópolis. A esa caterva de inválidos morales, sucedió posteriormente una exposición de obreros -fundidores, tipógrafos, herreros, hombreadores- la cual conquistó, en su hora, el éxito que se merecía. ${ }^{22}$

Para Castelnuovo, el éxito de Hebequer en el contexto nacional coincidió con el abordaje del mundo del trabajo. Sin embargo, a partir del viaje a Rusia algo cambia en la percepción de su obra. Tal como lo anunció el propio Castelnuovo, sus litografías fueron expuestas en Moscú y Leningrado, donde a juzgar por un titular del diario Crítica, la exposición contó con la asistencia de treinta mil trabajadores ("Ante treinta mil trabajadores de Leningrado expone el artista argentino Facio Hebequer”. Crítica, 2/8/1932. Archivo GFH). Esta nota anónima publicada en el diario de Botana contenía otro elemento de importancia: por primera vez, Facio Hebequer era definido como un pintor proletario que había elegido no exponer más en las galerías de Florida ni en los círculos oficiales, y había optado por "salir a la calle" y llevar su arte al mundo obrero ¿Por qué

${ }^{22}$ Castelnuovo, Elías. "Un pintor del bajo fondo porteño", en Metrópolis. De los escriben para decir algo, Buenos Aires, $\mathrm{N}^{\circ}$ 2, junio 1931, s/p. 
Hebequer dejaba de ser un "artista del pueblo" para a ser un "artista proletario"? Una de las claves para pensar en esta noción que comenzaba a ser debatida en las revistas culturales del período reside en la apelación a la figura del trabajador en tanto público. Las obras de Hebequer fueron recibidas por treinta mil proletarios y nadie más; un público constituido únicamente por obreros. Esas muestras itinerantes en las puertas de las fábricas no solo están produciendo subjetividades, generando conciencia o invocando la participación activa de la gente. Más enfáticamente, la exposición de las litografía está develando una carencia: el público que falta. Leningrado le ofrece a Hebequer un tipo de receptor que en la Argentina de las primeras décadas del siglo veinte no existe. O, desde la concepción de Castelnuovo, un público que todavía no existe.

En el viaje de Castelnuovo se opera entonces un doble desplazamiento: uno, espacial (hacia afuera, hacia la Rusia comunista) y el otro, temporal (hacia el futuro, el todavía no ser de la nación Argentina). Así, el viaje de Castelnuovo y su exposición de las litografías repone una de las cuestiones que acompañarán toda su producción teórica y literaria: la sinuosa relación entre la precariedad del proletariado nacional y la persecución de un arte proletario. El viaje le ofrece un atajo: solo después de exhibirlas en las fábricas soviéticas, esas litografías y su autor podrían devenir en arte proletario y artista proletario, respectivamente. $\mathrm{O}$ sea, para llegar a ese escalafón no era condición suficiente que la pintura -o el arte en general-, incorporara temáticas obreras, referentes del mundo obrero (recordemos que Hebequer ya había abordado el mundo del trabajo en el contexto nacional con lo cual "conquistó, en su hora, el éxito que se merecía"); tampoco que esas pinturas fueran recibidas por un público cualquiera. Los receptores debían ser necesariamente proletarios. O mejor, una serie de sujetos atravesados por una lógica, una racionalidad -ligada al trabajo- que los ordenara.

Si Argentina no podía ofrecerle esa masa trabajadora cohesionada, entonces el autor de Tinieblas va a buscarla a Rusia. La apuesta de Castelnuovo actualiza su posición en los debates de las revistas culturales respecto del proletariado y la forma de representarlo. Cabe insistir en este punto: para él, los 
CATEDRAL Tomada: Revista de crítica literaria latinoamericana / Journal of Latin American Literary Criticism Monumentos, monstruos y espectros: la figura del proletario en Argentina (1920-1950)

fundamentos del arte proletario no hay que buscarlos (por lo menos, no exclusivamente) en la inmanencia, en las leyes intrínsecas de su forma. Tampoco es suficiente su contenido, su vocación por temas estrictamente obreros. Tal como vemos en la escena que Castelnuovo modula a través de las obras de Hebequer, la condición necesaria está en la puesta en contacto de la producción artística con un sujeto articulado, aquello que justamente el campo social argentino no podía ofrecerle.

El viaje a Rusia, entonces, se articula como una forma de legitimar al artista y al arte proletario. Pero no solo en esas dos dimensiones se operan cambios. Del otro lado del lienzo también se proyectan algunas modificaciones relevantes. En las litografías de Hebequer aparecían los “monstruos” argentinos. Baja la mirada del propio Castelnuovo, una teratología (esa "caterva de inválidos morales") que va del manicomio a las fábricas. Solo después de ser expuestos y recibidos por los trabajadores en las fábricas rusas, esas presencias intimidantes se convierten en proletarios. Se vuelven cercanos, familiares. Si el contenido de la obra no garantizaba la articulación de un arte proletario, la recepción diferencial que se logra en Rusia opera cambios significativos en esa esfera. Es decir, es necesario que esas manchas (para insistir en el concepto de monstruo: aquello sin una forma definida) hayan atravesado el tamiz metropolitano (en este caso, la Moscú comunista) para que devengan proletarios, verdaderos trabajadores, identificables como tales.

De alguna manera, es en este cambio de dimensión de lo nacional a lo transnacional que se logra sortear la carencia de un proletariado argentino y evitar esa visión retórica a la que hacía alusión Portantiero. En la variación de escala, esos sujetos dispersos sin una teleología definida son incorporados a un proyecto. Y lo más relevante es que solo a partir de esta incorporación dejan de constituir ese objeto de piedad al que se refería Lamborghini, para formar parte del "destino de una nación". En el viaje de Castelnuovo no solo se legitiman las litografías de Hebequer en términos de arte proletario sino que es el propio proletariado el que toma una forma prototípica. Para el retorno de Castelnuovo, los cuerpos 
representados por Hebequer en sus litografías suspenden su estatuto de monstruos para constituir un nuevo estadio en la representación del proletariado nacional.

\section{Bibliografía}

Antelo, Raúl (2008). "Una crítica acéfala para la modernidad Iberoamericana", Revista Iberoamericana: Berlín; 129-136. Disponible en http://www.iai.spkberlin.de/fileadmin/dokumentenbibliothek/Iberoamericana/2008/Nr_30/30_ Antelo.pdf

Castelnuovo, Elías. Memorias. Buenos Aires: Ediciones culturales argentinas, 1974.

Lamborghini, Osvaldo. "El lugar del artista" en Lecturas Críticas: revista de investigación y y teorías literarias" en”, Año 1, N. 1, 1980.

Lobato, Mirta Zaida. La vida en las fábricas. Trabajo, protesta y política en una comunidad obrera, Berisso (1904-1970). Buenos Aires: Prometeo libros, 2004.

Lugones, Leopoldo. El Payador. Buenos Aires: Otero Impresores, 1916.

Lukács, Georg. Historia y consciencia de clase, México DF: Grijalbo, 1969.

Montaldo, Graciela. Zonas Ciegas: populismos y experimentos culturales en Argentina, Buenos Aires: Editorial Fondo de cultura económica, 2010.

. "Literatura de izquierda: humanitarismo y pedagogía", en Graciela Montaldo (comp.), Yrigoyen entre Borges y Arlt (1916-1930), vol. 2 de Literatura argentina siglo XX, David Viñas (dir.), Buenos Aires: Fundación Crónica General y Paradiso ediciones, 2006, pp. 324-344.

Portantiero, Juan Carlos, and María Teresa Granulia. Realismo Y Realidad En La Narrativa Argentina. Buenos Aires: EUDEBA, 2011.

Rancière, Jacques. "Política, identificación y subjetivación", en B. Arditi Karlik (ed.), El reverso de la diferencia: identidad y política, Caracas: Nueva 
CATEDRAL Tomada: Revista de crítica literaria latinoamericana / Journal of Latin American Literary Criticism Monumentos, monstruos y espectros: la figura del proletario en Argentina (1920-1950)

Visión, 2000.

Sarlo, Beatriz, Una modernidad periférica. Buenos Aires: 1920-1930, Buenos Aires: Nueva Visión, 1988. 